\title{
Social desirability and self-reported health risk behaviors in web-based research: three longitudinal studies
}

\author{
Rik Crutzen ${ }^{1 *}$, Anja S Göritz ${ }^{2}$
}

\begin{abstract}
Background: These studies sought to investigate the relation between social desirability and self-reported health risk behaviors (e.g., alcohol use, drug use, smoking) in web-based research.

Methods: Three longitudinal studies (Study 1: $N=5612,51 \%$ women; Study 2: $N=619,60 \%$; Study 3: $N=846$, 59\%) among randomly selected members of two online panels (Dutch; German) using several social desirability measures (Marlowe-Crowne Scale; Balanced Inventory of Desirable Responding; The Social Desirability Scale-17) were conducted.
\end{abstract}

Results: Social desirability was not associated with self-reported current behavior or behavior frequency. Sociodemographics (age; sex; education) did not moderate the effect of social desirability on self-reported measures regarding health risk behaviors.

Conclusions: The studies at hand provided no convincing evidence to throw doubt on the usefulness of the Internet as a medium to collect self-reports on health risk behaviors.

\section{Background}

This work sought to investigate the relation between social desirability and self-reported health risk behaviors (e.g., alcohol use, drug use, and smoking) in web-based research. Self-report measures are a common way of gathering data in research on health risk behaviors. In several commonly used planning models of health promotion [1,2], self-reports are used in several phases, for example, in the problem analysis (e.g., behavioral diagnosis) and in the evaluation of interventions (e.g., effectiveness). In tailored interventions, self-reports are used to tailor the intervention to respondents' behavior and determinants of this behavior [3,4]. One reason of why self-reports are used in research on health risk behaviors is that they require fewer resources (e.g., financial, logistical) and have higher specificity (e.g., quantity/frequency measures) compared to bio-medical measures such as hair testing and urine screening for drug use or an air carbon monoxide monitor for smoking. Another

\footnotetext{
* Correspondence: rik.crutzen@maastrichtuniversity.nl

${ }^{1}$ CAPHRI, Maastricht University, Maastricht, The Netherlands

Full list of author information is available at the end of the article
}

reason of why self-reports are used in research is that interventions are nowadays increasingly delivered through the Internet $[5,6]$. Internet-delivered interventions often rely on self-reports, because bio-medical measures are not consonant with grounds to deliver interventions through the Internet such as accessibility (24/7 worldwide), convenience (e.g., participating in the comfort of one's own home), and anonymity (e.g., no human contact).

A study by Kreuter, Presser, and Tourangeau [7] indicated an increase in the reporting of sensitive information in web-based questionnaires relative to conventional telephone interviewing, whereas another study found no differences when comparing web-based with paper-andpencil questionnaires [8]. On the one hand, some researchers stated that the social distance [9] and the impersonal nature of the Internet might inhibit trust development [10]. Link and Mokdad [11], for example, found the use of web-based research with the general public to be problematic (e.g., because of obtaining considerable variation in the estimates for heavy drinking). On the other hand, previous research indicated that smoking behavior can indeed be reliably assessed by 
self-reports obtained via the web $[12,13]$. Furthermore, McCabe and colleagues [14] provide strong evidence that web-based research can be used as an effective mode for collecting alcohol and other drug use data.

While some studies speak in favor of assessing alcohol use and addiction severity via the web $[15,16]$, others found underreporting of undesirable behaviors, such as drug use and alcohol use [17]. Social desirability may provide an explanation for these different findings. Social desirability is the tendency of respondents to distort self-reports in a favorable direction, for example, by providing responses that - to their belief - are consistent with social norms and expectations [18].

There has been a long discussion in the literature whether social desirability is a personality trait or a situational strategy [19]. Previous research using latent state-trait models indicates that the largest proportion of variance in responses is attributable to differences in the trait. A small but significant proportion of variance is due to situation-specific conditions [20]. A condition that tends to enhance the possibility of social desirability bias is a highly sensitive topic [21]. Moreover, significant relationships between social desirability and self-reports of risk-taking behavior have been revealed previously [22]. Hence, it is reasonable to assume that many areas of public health, particularly self-reports of health risk behaviors, are prone to social desirability bias. If selfreported measures are indeed influenced by social desirability, controlling for social desirability may remove some of the error due to the use of self-report measures and therewith improve the validity of these measures [23].

Previous research found minimal evidence of an influence of social desirability on scores from two self-report measures of measuring physical activity in young adults [24] and no evidence for a social desirability bias with a self-report condom use scale [25]. Nevertheless, these studies were not web-based, thereby ignoring the social distance and impersonal nature of the Internet. Mode comparison studies (i.e., in which web-based assessment is compared with, for example, paper-and-pencil assessment $[26,27]$ or with telephone interviewing [28]) generally have relied on one of three different designs: randomization after recruitment (true experimental design), randomization before recruitment (where there may be differences in response between modes), and a test-retest design (where respondents need to answer questions in two or more modes consecutively). A recent report on online panels by the American Association for Public Opinion Research [29] concluded that, regardless of design, there were higher reports of socially undesirable attitudes and behaviors in selfreported web-based questionnaires than in face-to-face interviews. For example, web-based questionnaires yielded higher reports of smoking [30] and alcohol use [31]. These studies compared different modes regarding self-reports of health risk behaviors (e.g., differences in prevalence rates) and attributed the studies' results to characteristics of that mode. In other words, these studies assumed that certain modes lead to more or less socially desirable responding. Hence, the focus of these studies was not on the influence of social desirability itself. It is possible, for example, that there were other factors, besides social desirability, that led to differences in reports of health risk behaviors. In contrast to the work at hand, these studies did not investigate whether differences in social desirability resulted in differences in self-reports of health risk behaviors.

If social desirability is found out to be an issue in web-based research, this would raise concerns about the validity of web-based research on health risk behaviors. Therefore, in the work at hand we were specifically interested in the relationship between social desirability and the self-reporting of health risk behaviors in webbased research. We investigated the association between social desirability measures and self-reported health risk behaviors. Hence, the following research question was put forward:

To what extent is social desirability associated with self-reported health risk behaviors in web-based research?

Because of the social distance [9] and the impersonal nature of the Internet [10], we did not expect social desirability to have a biasing influence in web-based research on health risk behaviors. Additionally, we investigated potential moderating effects of socio-demographics on the effects of social desirability on self-reports of health risk behaviors. In line with a meta-analysis about social desirability distortion [32], we did not expect any moderating effects of socio-demographics.

Due to the explorative nature of our research, we collected data in three longitudinal studies among randomly selected members of two online panels using several social desirability measures. In the first study, the traditional social desirability measure was used: the Marlowe-Crowne Scale [33]. For this measure, items were selected from personality questionnaires that described behaviors that were highly desirable but unlikely to be true or undesirable but likely to be true. High scorers on the Marlowe-Crowne Scale are more amendable to social influence compared to low scorers. Therefore, higher scores are probably related to impression management; a tendency to intentionally distort one's self-image to be perceived favorably by others [34].

Gawronski and colleagues [35] argued, however, that the Marlowe-Crowne Scale may be too general to capture motivational distortions in self-reports and a more differentiated social desirability measure distinguishing 
between self-deception and impression management may be needed. Self-deception is an unintentional propensity to portray oneself in a favorable light, manifested in positive but honestly believed self-descriptions [34]. Impression management, by contrast, is people's tendency to intentionally distort their self-presentation to be perceived favorably by others The Balanced Inventory of Desirable Responding (BIDR) [36] appeared to be useful for our purposes, since this measure has two subscales measuring both self-deception (BIDR-SE) and impression management (BIDR-IM). The BIDR-IM was used in the second study because this subscale is more closely related to the Marlowe-Crowne Scale and is deemed to be instrumental for our purposes.

Another critique on the Marlowe-Crowne Scale says this scale reflects the social standards of the late $1950 \mathrm{~s}$ (e.g., "I am always courteous, even to people who are disagreeable.") and is less appropriate to be used nowadays [37]. To remedy this limitation, the Social-Desirability Scale-17 (SDS-17) was developed [37]. This is a new scale in the Marlowe-Crowne style, but with up-todate contents. To avoid falling prey to potential problems of validity with the Marlowe-Crowne Scale, in the third study, we used the SDS-17 next to both subscales of the BIDR. We hypothesized - in line with Stöber [37] - that the SDS-17 is more highly correlated with the BIDR-IM than with the BIDR-SE. Besides differences in correlations among scales, we did not hypothesize differences among the scales regarding their relationship to self-reports of health risk behaviors, since we did not expect social desirability to have an influence in webbased research on health risk behaviors in the first place.

\section{Study 1: Methods}

A longitudinal study was conducted to investigate the relation between social desirability and self-reported health risk behaviors in web-based research. Data were collected through the LISS panel http://www.lissdata.nl. The reference population for the LISS panel is the Dutch speaking population permanently residing in the Netherlands. In co-operation with Statistics Netherlands addresses were drawn from the nationwide address frame. The sample from the population registers includes individuals who do not have Internet access. These participants were provided equipment to access the Internet via a broadband connection. Sample members with small band Internet access were provided with broadband [38]. There was no ethics approval for this study specifically, but for the umbrella project which was conducted by an external party (CentERdata; http:// www.centerdata.nl/en). Relevant ethical safeguards were met with regard to the participant confidentiality and consent.

\section{Procedure and Respondents}

Data on social desirability were collected between May 2008 and August 2008 (T1). In total, 8,722 panel members were invited. Of those, 6,808 initiated the questionnaire (response rate $78.1 \%$ ) and 6,766 completed the social desirability measure (completion rate $99.4 \%$ ). This initial sample of 6,766 panel members was re-invited between November 2008 and December 2008 (T2) - to complete the follow-up measures on health risk behaviors. Of those, 5,635 initiated the questionnaire (response rate 83.3\%) and 5,612 completed the health risk behavior measures (99.6\%). This resulted in a final sample of 5,612 respondents, who were included in the analyses (Table 1).

\section{Measures \\ Socio-demographics}

Besides age and sex, two predictors of socio-economic status were measured: personal net monthly income (in Euros) and level of education. A detailed description of the procedure that we used to determine personal net monthly income can be found elsewhere [39]. Level of education was categorized according to the definitions of Statistics Netherlands, resulting in six categories: primary school, intermediate secondary education (US: junior high school), higher secondary education/preparatory university education (US: senior high school), intermediate vocational education (US: junior college), higher vocational education (US: college), and university. Sociodemographics of all panel members were known in advance. This provided the opportunity to conduct attrition analyses regarding socio-demographic variables.

\section{Social desirability}

Social desirability was measured by the shortened version of the Marlowe-Crowne Scale [33], which has been validated previously [40]. This scale consists of ten true/ false statements, e.g., "I am always courteous, even to people who are disagreeable". The scale score ranges from zero to ten. A high score indicates a high tendency to provide socially desirable responses.

\section{Health risk behaviors}

Two aspects with regard to health risk behaviors were assessed: (1) current behavior and (2) behavior frequency among those who carried out the behavior in question. Current behavior was assessed for alcohol use (Have you had a drink containing alcohol during the last seven days), drug use (Have you used ... over the past month?), and smoking (Do you smoke?). Sedatives (e.g., valium), soft drugs (e.g., hashish, marijuana), XTC, hallucinogens (e.g., LSD, magic mushrooms), and hard drugs (e.g., cocaine, heroine) were included as separate items regarding drug use. XTC was considered as a separate category because of its high rate of use in the Netherlands [41]. 
Table 1 Sample characteristics (Study 1; $N=5,612$ )

\begin{tabular}{|c|c|c|}
\hline Socio-demographics & & \\
\hline Age & & $M=46.9(16.0)$ \\
\hline \multirow[t]{2}{*}{ Sex } & Female & $51.2 \%$ \\
\hline & Male & $48.8 \%$ \\
\hline Personal net monthly income & (in Euros) & Median $=1,300$ \\
\hline \multirow[t]{6}{*}{ Level of education } & Primary school & $9.7 \%$ \\
\hline & Intermediate secondary education & $26.4 \%$ \\
\hline & Higher secondary education/preparatory university education & $11.0 \%$ \\
\hline & Intermediate vocational education & $23.1 \%$ \\
\hline & Higher vocational education & $22.3 \%$ \\
\hline & University & $7.5 \%$ \\
\hline Social desirability (Marlowe-Crowne) & & $\begin{array}{l}M=5.9(1.5) \\
\text { (Scale: } 0-10)\end{array}$ \\
\hline \multicolumn{3}{|l|}{ Health risk behaviors } \\
\hline \multirow[t]{7}{*}{ Current behavior } & Alcohol use & $72.7 \%$ \\
\hline & Sedatives & $4 \%$ \\
\hline & Soft drugs & $3 \%$ \\
\hline & XTC & $0.5 \%$ \\
\hline & Hallucinogens & $0.2 \%$ \\
\hline & Hard drugs & $0.5 \%$ \\
\hline & Smoking & $35.6 \%$ \\
\hline \multirow[t]{7}{*}{ Frequency } & Alcohol use & $M=3.4(2.2)$ \\
\hline & Sedatives & $M=13.3(27.6)$ \\
\hline & Soft drugs & $M=13.4(26.0)$ \\
\hline & XTC & $M=1.5(0.9)$ \\
\hline & Hallucinogens & $M=1.2(0.6)$ \\
\hline & Hard drugs & $M=2.9$ \\
\hline & Smoking & $M=11.6(8.1)$ \\
\hline
\end{tabular}

Behavior frequency was also assessed for alcohol use (On how many of the past seven days did you have a drink containing alcohol?), drug use (How often have you used ... over the past month?), and smoking (How many cigarettes (including rolling tobacco) do you smoke on average per day?). According to the obtained self-reports of current behavior, sedatives, soft drugs, XTC, hallucinogens, and hard drugs were included as separate items regarding frequency of drug use.

\section{Analyses}

First, attrition analyses, by means of t-tests and $\chi^{2}$-tests, were conducted to test for possible differences between retainees and drop-outs with regard to socio-demographics. Second, multiple regression analyses were conducted. Current behavior (dichotomous variables; logistic regression analyses) and its frequency (linear variables; linear regression analyses) were the dependent variables. The linear dependent variables were subjected to Box-Cox-transformations to meet the assumption of normality [42]. Age, sex, personal net monthly income, education, and social desirability (at T1) were included in the model as predictors of the dependent variables (at
T2). Moreover, interaction terms between socio-demographics (i.e., age, sex, personal net monthly income, and education) and social desirability were added to test for possible moderating effects [43]. Odds ratios were converted into Cohen's $d$ (as described by Chinn [44]) to be able to report standardized effect sizes.

\section{Study 1: Results}

Retainees in the final sample did not differ in sex $\left(\chi^{2}(1\right.$, $N=6,603)=.23, p=.64)$, personal net monthly income $(\mathrm{t}(6,285)=.72, p=.47)$, and education $\left(\chi^{2}(5, N=6,603)\right.$ $=10.24, p=.07)$ from panel members who droppedout. Those who dropped-out, however, were younger than those who completed both questionnaires (42.1 versus 46.9 years, $\mathrm{t}(6,601)=9.16, p<.01)$.

Social desirability was not associated with reported current behavior or behavior frequency (Additional file 1). The only exception was a positive effect of social desirability on the self-reported use of hard drugs $(\mathrm{OR}=4.86$, $p<.01,95 \% \mathrm{CI}=1.88-12.56)$. The broad confidence interval reflects the small number of participants concerned [45], since only $0.5 \%$ of our sample reported having used hard drugs over the past month (Table 1). 
Most interactions terms between socio-demographics and social desirability were not significantly associated with current health risk behaviors or health risk behavior frequencies. The only exception was an interaction between education and social desirability: Those at the lowest educational level (i.e., primary school) and a high social desirability score were more likely to report having used hard drugs over the past month $(\mathrm{OR}=2.47$, $p<.05,95 \% \mathrm{CI}=1.02-5.99)$. The broad confidence interval reflects the small number of participants concerned regarding hard drug use.

\section{Study 2: Methods}

A second study was conducted to investigate the robustness of the first study's findings on another large sample, with another social desirability measure and implementing a larger time lag between the measurement of social desirability and self-reported health risk behaviors.

The Balanced Inventory of Desirable Responding (BIDR) [36], which has been validated in Germany [46], was used to measure social desirability. Furthermore, a different online panel was used than in the previous study, namely the WiSo-Panel http://www.wisopanel.uni-erlangen.de. This panel holds demographically heterogeneous participants from all walks of life, of which $99 \%$ are German speaking Germans, Austrians, and Swiss. People have been recruited for this panel from different sources using a wide range of methods - both probabilistic [47] and nonprobabilistic (e.g., newsletters, participants in one-shot web-studies, word-of-mouth, search engines). This study was approved by the German Research Foundation, which included an approval of ethical aspects.

\section{Procedure and Respondents}

Data regarding social desirability were collected in October and November 2008 (T1). In total, 5,857 panel members were invited by e-mail. Of those, 1,694 initiated the questionnaire (response rate $28.9 \%$ ) and 1,438 completed the social desirability measure (completion rate $84.9 \%$ ). The sample of who had completed the social desirability measure was re-invited - in December 2009 (T2) - to complete the follow-up measures regarding health risk behaviors. In between $\mathrm{T} 1$ and T2, 57 people had left the panel; therefore the remaining 1,381 panel members were invited to T2. Of those, 644 called up the questionnaire (response rate 46.6\%), and of those who respondended, 619 completed the health risk behavior measures (completion rate $96.1 \%$ ). This resulted in a final sample of 619 respondents (Table 2).

\section{Measures}

\section{Socio-demographics}

Age, sex, and level of education. Education was categorized in line with the German school system: no degree
Table 2 Sample characteristics (Study 2; $N=619$ )

\begin{tabular}{lll}
\hline Socio-demographics & & \\
\hline Age & & $\mathrm{M}=39.1(11.7)$ \\
Sex & Female & $60.4 \%$ \\
Level of education & Male & $39.6 \%$ \\
& No degree & $1.3 \%$ \\
& Nine years of school & $10.3 \%$ \\
& Vocational qualification & $33.1 \%$ \\
& University qualification & $36.2 \%$ \\
& University & $18.4 \%$ \\
& Doctorate & $0.6 \%$ \\
\hline Social desirability (BIDR-IM) & & $\mathrm{M}=3.6(1.0)$ \\
& & $(\mathrm{Scale:} 1-7)$ \\
\hline Health risk behaviors & & \\
Current behavior & Alcohol use & $59.0 \%$ \\
& Smoking & $33.9 \%$ \\
\cline { 2 - 3 } Frequency & Alcohol use & $\mathrm{M}=2.6(1.8)$ \\
& Smoking & $\mathrm{M}=16.3(9.7)$ \\
\hline
\end{tabular}

(i.e., only primary school), nine years of school (US: junior high school), vocational qualification (US: senior high school), university qualification (US: senior high school), university (US: Bachelor's and Master's degree), and doctorate (US: PhD). Socio-demographics of all panel members were known in advance. This provided the opportunity to conduct attrition analyses regarding socio-demographics.

\section{Social desirability}

Social desirability was measured by the impression management scale of the BIDR (BIDR-IM). Respondents are required to indicate their agreement with ten statements about themselves on a 7-point scale, with 1 denoting "fully disagree" and 7 denoting "fully agree". After reversing negatively keyed items, the score on this scale ranges from one to seven. A high score indicates a high tendency of impression management.

\section{Health risk behaviors}

Two aspects of health risk behaviors were assessed: (1) current behavior and (2) behavior frequency among those who carried out the behavior in question. Current behavior was assessed for alcohol use (Have you had a drink containing alcohol during the last seven days) and smoking (Do you smoke?). Behavior frequency was also assessed for alcohol use (On how many of the past seven days did you have a drink containing alcohol?) and smoking (How many ... do you smoke on average per day?). With regard to smoking, we added cigarettes and hand-rolled cigarettes to determine the number of cigarettes (including rolling tobacco) [48].

\section{Analyses}

Attrition analyses and multiple regression analyses were comparable to those conducted in the first study. 


\section{Study 2: Results}

Retainees in the final sample did not differ in sex $\left(\chi^{2}(1\right.$, $N=1,505)=1.96, p=.16$ ) from panel members who had dropped-out. Those who dropped-out, however, were younger than those who completed both questionnaires $(35.0$ versus 39.1 years, $\mathrm{t}(1,501)=6.50, p<.001)$. Moreover, drop-outs were more likely to have a university qualification $(46.1 \%$ versus $36.2 \%$, OR $=1.51, p<$ $.01,95 \%$ CI 1.23 - 1.85).

Social desirability, as measured by BIDR-IM, was not associated with reported current behavior or behavior frequency (Table 3). Socio-demographics (i.e., age, sex, and education) did not moderate the effect of social desirability on self-reported health risk behaviors and their frequency.

\section{Study 3: Methods}

To throw more light on the issue of the results depending on the choice of scale, this study employed several social desirability measures.

A five-wave longitudinal study was conducted; the first four waves were used to measure social desirability and the fifth wave was used to obtain self-reports on health risk behaviors. Four separate waves were used to avoid contamination between different social desirability measures as well as to determine the re-test reliability of measuring social desirability. A random sample of the same panel but consisting of different panel members as in Study 2 was used. This study was approved by the German Research Foundation, which included an approval of ethical aspects.

\section{Procedure and Respondents}

Data on social desirability were collected in November 2008 (T1), December 2008 (T2), March 2009 (T3), and April 2009 (T4). In total, 3,201 panel members were invited by e-mail. Of those, 2,037 initiated the

Table 3 Effect of social desirability on self-reported health risk behaviors (Study 2; $N=619$ )

\begin{tabular}{|c|c|c|c|c|}
\hline & \multicolumn{2}{|c|}{ Current behavior $^{1}$} & \multicolumn{2}{|c|}{ Frequency $^{1}$} \\
\hline & Alc & Smo & Alc & Smo \\
\hline Predictors & $d$ & $d$ & B & ß \\
\hline Age & .00 & .01 & $.28^{*}$ & $.26^{*}$ \\
\hline Sex & $-.35^{*}$ & .15 & $-.20^{*}$ & .08 \\
\hline Education $^{2}$ & 6.89 & $21.00^{*}$ & .09 & -.12 \\
\hline SocDes $^{3}$ & .00 & -.43 & -.10 & -.50 \\
\hline Age $\times$ SocDes & .01 & .00 & -.03 & .07 \\
\hline Sex $\times$ SocDes & .11 & .10 & .08 & .15 \\
\hline Education $\times$ SocDes $^{2}$ & 2.83 & .06 & -.05 & .36 \\
\hline$\overline{R^{2}}$ & .10 & .12 & .15 & .11 \\
\hline
\end{tabular}

${ }^{1}$ Alc $=$ Alcohol use; Smo $=$ Smoking; ${ }^{2}$ Wald statistic instead of Cohen's $d ;$

${ }^{3}$ Social desirability; ${ }^{*} p<.05$. questionnaire (response rate 63.6\%), and of those responding, 1,829 completed the social desirability measure in T1 (completion rate $89.8 \%$ ). In T2 we invited the remaining 3,168 panel members from the original sample. Of those, 1,875 initiated the questionnaire (response rate 59.2\%), and of those responding, 1,733 completed the social desirability measure (completion rate 92.4\%). In T3 we invited the then remaining 3,136 panel members from the original sample. Of those, 1,769 initiated the questionnaire (response rate 56.4\%), and of those responding, 1,362 completed the social desirability measure (completion rate $77.0 \%$ ). In $\mathrm{T} 4$ the then remaining 3,124 panel members from the original sample were invited. Of those, 1,630 called up the questionnaire (response rate 52.2\%), and of those responding, 1,481 completed the social desirability measure (completion rate $90.9 \%$ ). A total of 2,493 panel members completed at least one of the social desirability measures. Of this group, those 2,390 panel members who were still members of the panel were invited in December 2009 (T5) to complete self-reports on their health risk behaviors. Of those invited, 996 initiated the questionnaire (response rate 41.7\%), and of those responding, 846 completed both health risk behavior measures (completion rate $84.9 \%)$. This resulted in a final sample of 846 respondents (Table 4).

\section{Measures}

Socio-demographics and health risk behaviors were measured in the same fashion as in Study 2. The following social desirability measures were used:

\section{T1 (BIDR-IM1)}

Impression management scale of the BIDR (the same one used as in Study 2).

\section{T2 (SDS-17)}

Social-Desirability Scale-17, which has also been validated in Germany [37]. As recommended by Stöber [37], one item was deleted from the final version of the SDS-17, leaving sixteen true/false statements (e.g., "I never hesitate helping someone in case of emergency"). The scale score ranges from zero to sixteen, with a high score indicating a high tendency to give socially desirable responses.

\section{T3 (BIDR-IM2)}

Impression management scale of the BIDR (the same one used as in T1 to assess temporal stability of this scale between $\mathrm{T} 3$ and $\mathrm{T} 1$ ).

\section{T4 (BIDR-SE)}

Self-deceptive enhancement scale of the BIDR. Similar to the impression management scale (which is the other scale of the BIDR), respondents need to indicate their agreement with ten statements about themselves on a 7point scale, with 1 denoting "fully disagree" and 7 denoting "fully agree". After reversing negatively keyed 
Table 4 Sample characteristics (Study 3; $N=846$ )

\begin{tabular}{lll}
\hline Socio-demographics & & \\
\hline Age & & $\mathrm{M}=43.9(11.7)$ \\
Sex & Female & $58.7 \%$ \\
Level of education & Male & $41.3 \%$ \\
& No degree & $0.6 \%$ \\
& Nine years of school & $11.3 \%$ \\
& Vocational qualification & $34.4 \%$ \\
& University qualification & $23.5 \%$ \\
& University & $28.8 \%$ \\
& Doctorate & $1.5 \%$ \\
\hline Social desirability & BIDR-IM1 & $\mathrm{M}=3.9(1.0)$ \\
& & (Scale: $1-7)$ \\
& SDS-17 & $\mathrm{M}=10.2(3.1)$ \\
& & (Scale: $0-16)$ \\
& BIDR-IM2 & $\mathrm{M}=3.9(1.1)$ \\
& & (Scale: $1-7)$ \\
& BIDR-SE & $\mathrm{M}=4.2(0.8)$ \\
& & (Scale: $1-7)$ \\
\hline Health risk behaviors & & \\
\cline { 2 - 3 } Current behavior & Alcohol use & $66.1 \%$ \\
& Smoking & $33.8 \%$ \\
\cline { 2 - 3 } Frequency & Alcohol use & $\mathrm{M}=2.7(1.9)$ \\
& Smoking & $\mathrm{M}=15.4(9.0)$ \\
\hline
\end{tabular}

items, the score on this scale ranges from one to seven, with a high score indicating a high tendency of selfdeceptive enhancement.

\section{Analyses}

Attrition analyses and multiple regression analyses proceeded comparably to those conducted in the previous studies. Before conducting these analyses, however, Pearson correlation coefficients among the three social desirability measures were calculated (Table 5). These correlations were comparable in size to those in Musch and colleagues [46]. Moreover, the intercorrelations among the different social desirability measures followed an expectable pattern: Using the same measure at two time points (i.e., re-test reliability of BIDR-IM) yields the highest correlation (.74), followed by intermediate

Table 5 Correlations between social desirability measures (Study 3; $N=846$ )

\begin{tabular}{llcccc}
\hline Wave & Measure & BIDR-IM1 & SDS-17 & BIDR-IM2 & BIDR-SE \\
\hline T1 & BIDR-IM1 & - & $.55^{*}$ & $.74^{*}$ & $.28^{*}$ \\
& $(\alpha=.74)$ & $\mathrm{N}=1820$ & $\mathrm{~N}=1306$ & $\mathrm{~N}=1048$ & $\mathrm{~N}=1093$ \\
$\mathrm{~T} 2$ & SDS-17 & & - & $.60^{*}$ & $.40^{*}$ \\
& $(\alpha=.72)$ & & $\mathrm{N}=1733$ & $\mathrm{~N}=1057$ & $\mathrm{~N}=1117$ \\
$\mathrm{~T} 3$ & BIDR-IM2 & & & - & $.31^{*}$ \\
& $(\alpha=.72)$ & & & $\mathrm{N}=1358$ & $\mathrm{~N}=1000$ \\
$\mathrm{~T} 4$ & BIDR-SE & & & & - \\
& $(\alpha=.68)$ & & & & $\mathrm{N}=1477$ \\
\hline
\end{tabular}

${ }^{*} p<.01$ (2-tailed) correlations between two different social desirability measures (.55 for SDS-17 and BIDR-IM1, .60 for SDS17 and BIDR-IM2, .40 for SDS-17 and BIDR-SE), followed by the lowest correlations between two complementary scales that are supposed to capture different facets of social desirability (.28 for BIDR-IM1 and BIDR-SE, .40 for BIDR-IM2 and BIDR-SE). Moreover, the re-test reliability of BIDR-IM (. 74) was about as large as the internal consistency of the measurement at either time point (.74 for BIDR-IM1 and .72 for BIDRIM2), which speaks to the quality of the measurement. To prevent multicollinearity from distorting results, separate regression models were created for each social desirability measure, resulting in four final models per dependent variable.

\section{Study 3: Results}

Panel members who dropped out were more likely to be women $\left(63.2 \%\right.$ versus $58.7 \%, \chi^{2}(1, N=1,964)=3.94, p$ $<.05)$ and younger $(42.2$ versus 43.9 years, $\mathrm{t}(1,960)=$ $2.56, p=.01)$ than retainees in the final sample. Moreover, drop-outs were more likely to have a vocational qualification $(34.4 \%$ versus $25.9 \%, \mathrm{OR}=.48, p=.04$, $95 \%$ CI .24 - .97).

By and large, the social desirability measures were not associated with self-reported current behavior or behavior frequency (Additional file 2). Moreover, the interactions terms between socio-demographics (i.e., age, sex, and education) and social desirability were not significantly associated with health risk behaviors or health risk behavior frequencies. The only exceptions were two interactions between education and the self-deceptive enhancement scale: Those at the higher educational level and a high unintentional propensity to portray oneself in a favorable light reported lower behavior frequency regarding alcohol use and smoking.

\section{Discussion}

Three longitudinal studies revealed no meaningful associations between social desirability and self-reported health risk behaviors in web-based research. This is in line with our hypothesis. Moreover, in agreement with a meta-analysis on social desirability distortion [32], sociodemographics by and large did not moderate the relationship between social desirability and self-reported health risk behaviors. The only exception was education, which moderated the impact of self-deceptive enhancement on self-reported behavior frequency. This unanticipated effect warrants further investigation. However, given the high number of moderator tests conducted, this one effect might well be due to chance. Furthermore, there were no notable differences among the correlations of different social desirability measures with self-reported health risk behaviors. In pattern and size, 
these correlations were in line with previous research $[37,46]$. A possible explanation for the lack of a noteworthy association between social desirability and selfreported health risk behaviors is that respondents provide accurate self-reports of even undesirable behaviors, because the online setting increases their perceived privacy. An interviewer-administered questionnaire, by contrast, requires disclosure in front of an interviewer: The resulting shame might make underreporting undesirable behaviors more likely [49].

The studies at hand are potentially limited because current behavior and behavior frequency were measured by single items. Multiple-item measures might be more prone to social desirability distortion, because they increase the saliency of the undesirable behavior by way of repetition. Thus, our main outcome that people with tendencies of socially desirable self-presentation report the same degree of undesirable health risk behaviors than people with fewer tendencies of socially desirable self-presentation might not hold if multiple-item measures of health risk behaviors were used. Future research needs to shed light on this issue.

A strong point of the work at hand is the size and diversity of the samples. In contrast to previous research [23-25], we used three different samples from two demographically heterogeneous online panels from two different countries, providing the opportunity for generalization across samples. Outcomes across these three studies were largely congruent, which speaks in favor of the robustness of our findings. Thanks to the large sample sizes, the confidence intervals of the effects regarding social desirability were narrow (Additional files 1 and 2; Table 3), indicating an accurate estimation of effects [50]. Another benefit of the studies at hand is that they were longitudinal. Assessing participants' tendencies to present themselves in a socially desirable manner and obtaining their self-reports on socially undesirable health risk behaviors was spread apart in time. Therefore, our measurements are unlikely to be distorted by participants' unintentional and intentional attempts at portraying themselves as consistent, as might have happened had we obtained both sets of data in the same session. Finally, we used three different measures (Marlowe-Crowne Scale, BIDR, SDS-17) of social desirability, which pleads to the robustness of our findings across measures.

Although social desirability was not found to be consistently related to self-reported health risk behaviors in web-based research, this does not imply that self-report measures are equal to bio-medical measures in terms of validity. Previous research that compared self-report measures to bio-medical measures found mixed results. While predictions of urine drug screen had poor correspondence with self-report data [51,52], for example, there was a high consistency of self-report data with hair testing for drug use [53], a dipstick method assessing nicotine intake [54], and biological markers among alcohol-dependent patients [55]. This being only a general caution as this work was not about the comparative validity of self-reports versus bio-medical measures.

Furthermore, perhaps participants feared that their identity might be revealed by legal force, which possibly influences the validity of responses regarding illegal behavior (i.e., drug use). However, this fear would probably have led to more socially desirable responding, while the studies at hand revealed no meaningful associations between participants' self-reports and social desirability.

Last but not least, five final points need to be made. (1) Social desirability bias is not the only source of measurement error. Recall error, for example, may also lead to measurement error as may question format [56]. (2) There was mild selective drop-out in all studies. Those who dropped-out, for example, were younger than retainees. First, a certain level of drop-out is ubiquitous in longitudinal research, also on the web [57]. Second, the dropout in these studies seems to be innocuous, because socio-demographics did not moderate the impact of social desirability on self-reported health risk behaviors. (3) It is possible that some respondents might not have perceived alcohol use, drug use, and smoking as socially undesirable. Hence, they had no reason to tilt their selfreports into a favorable direction. However, this possibility alone can hardly account for the overall finding of a lack of a meaningful association between self-reported health risk behaviors and social desirability in as many as three samples. At any rate, future studies should examine the association between social desirability and self-reported health risk behaviors other than the ones looked at in the studies at hand. (4) These studies failed to find meaningful associations between social desirability and self-reported health risk behaviors. Because an absence of evidence of an association does not equal evidence of absence of an association, future research is not precluded from revealing such an association after all. However, the fact that the self-reports of different health risk behaviors were not considerably influenced by social desirability in as many as three studies that were longitudinal in nature and relied on large and heterogeneous samples gives us confidence in the robustness of our results. (5) This conclusion is backed up by the fact that in the three studies at hand that employed several measures of social desirability, a high number of statistical tests were conducted which entails a high likelihood of obtaining false positive results. Taking this inflation of Type I error into account, even the few small associations found between social desirability and self-reported health risk behaviors might well be due to chance. 


\section{Conclusions}

These studies do not throw doubt on the usefulness of the Internet as a medium to collect self-reports on health risk behaviors.

\section{Additional material}

Additional file 1: Results Study 1 . Effect of social desirability on selfreported health risk behaviors (Study $1 ; N=5,612$ ).

Additional file 2: Results Study 3 . Effect of social desirability on selfreported health risk behaviors (Study $3 ; N=846$ ).

\section{Acknowledgements}

This paper draws on data of the LISS panel of CentERdata (Study 1). This work was in part supported by DFG grant GO 1107/4-1 to Göritz (Studies 2 and 3). We thank the companies ForschungsWerk, YouGovPsychonomics, PSYMA GROUP, Toluna, Smart-Research, and VZnet Netzwerke for help in recruiting part of the participants for Studies 2 and 3 .

\section{Author details}

${ }^{1}$ CAPHRI, Maastricht University, Maastricht, The Netherlands. ${ }^{2}$ Work, Industrial \& Organizational Psychology, University of Würzburg, Würzburg, Germany.

\section{Authors' contributions}

Both authors substantially contributed to the conception and design of the study, and interpretation of data. RC drafted the manuscript and AG substantially contributed to revising it. Both authors approved the final version of the manuscript.

\section{Competing interests}

The authors declare that they have no competing interests.

Received: 25 June 2010 Accepted: 23 November 2010 Published: 23 November 2010

\section{References}

1. Green LW, Kreuter MW: Health program planning: an education and ecological approach New York: McGraw-Hill; 2005.

2. Bartholomew LK, Parcel GS, Kok G, Gottlieb NH: Planning health promotion programs: an Intervention Mapping approach San Francisco: Jossey-Bass; 2006

3. De Vries $\mathrm{H}$, Brug J: Computer-tailored interventions motivating people to adopt health promoting behaviors: Introduction to a new approach. Patient Educ Couns 1999, 36:99-105.

4. Brug J, Oenema A, Kroeze W, Raat H: The internet and nutrition education: challenges and opportunities. Eur J Clin Nutr 2005, 59: S130-S139.

5. Webb TL, Joseph J, Yardley L, Michie S: Using the Internet to promote health behavior change: a meta-analysis of the impact of theoretical basis, use of behavior change techniques, and mode of delivery on efficacy. J Med Internet Res 2010, 12:e4.

6. Bock BC, Graham AL, Whiteley JA, Stoddard JL: A review of web-assisted tobacco interventions (WATIs). J Med Internet Res 2008, 10:e39.

7. Kreuter F, Presser S, Tourangeau R: Social desirability bias in CATI, IVR, and Web surveys: the effect of mode and question sensitivity. Public Opin Quart 2008, 72:847-865.

8. Miller ET, Neal DJ, Roberts LJ, Baer JS, Cressler SO, Metrik J, Marlatt GA: Testretest reliability of alcohol measures: is there a difference between Internet-based assessment and traditional methods? Psychol Addict Behav 2002, 16:56-63.

9. Newman JC, Des Jarlais DC, Turner CF, Gribble J, Cooley P, Paone D: The differential effects of face-to-face and computer interview modes. Am J Public Health 2002, 92:294-297.

10. Joinson AN: Knowing me, knowing you: reciprocal self-disclosure in Internet-based surveys. Cyberpsychol Behav 2001, 4:587-591.
11. Link MW, Mokdad AH: Effects of survey mode on self-reports of adult alcohol consumption: a comparison of mail, web, and telephone approaches. J Stud Alcohol Drugs 2005, 66:239-245.

12. Brigham J, Lessov-Schlaggar CN, Javitz HS, Krasnow RE, McElroy M, Swan GE: Test-rest reliability of web-based retrospective self-report of tobacco exposure and risk. J Med Internet Res 2009, 11:e35.

13. Graham AL, Papandonatos GD: Reliability of Internet- versus telephoneadministered questionnaires in a diverse sample of smokers. J Med Internet Res 2008, 10:e8.

14. McCabe SE, Boyd CJ, Couper MP, Crawford S, D'Arcy H: Mode effects for collecting alcohol and other drug use data: web and U.S. mail. J Stud Alcohol Drugs 2002, 63:755-761.

15. Khadjesari Z, Murray E, Kalaitzaki E, White IR, McCambridge J, Godfrey C, Wallace P: Test-retest reliability of an online measure of past week alcohol consumption (the TOT-AL), and comparison with face-to-face interview. Addict Behav 2009, 34:337-342.

16. Brodey BB, Rosen CS, Winters KC, Brodey IS, Sheetz BM, Steinfeld RR, Kaminer $Y$ : Conversion and validation of the Teen-Addiction Severity Index (T-ASI) for Internet and automated-telephone self-report administration. Psychol Addict Behav 2005, 19:54-61.

17. Tourangeau R, Yan T: Sensitive questions in surveys. Psychol Bull 2007, 133:859-883.

18. Paulhus DL: Measurement and control of response bias. In Measures of personality and social psychological attitudes. Edited by: Robinson JP, Shaver PR, Wrightsman LS. San Diego: Academic press; 1991:17-59.

19. Zerbe WJ, Paulhus DL: Socially desirable responding in organizational behavior: a reconception. Acad Manage Rev 1987, 12:250-264.

20. Schmitt MJ, Steyer R: A latent state-trait model (not only) for social desirability. Pers Indiv Differ 1993, 14:519-529.

21. Mick DG: Are studies of dark side variables confounded by socially desirable responding? The case of materialism. J Consum Res 1996, 23:106-119.

22. Kogan N: Risk taking: A study in cognition and personality New York: Holt, Rinehart \& Winston; 1964.

23. Jago R, Baranowski T, Baranowski JC, Cullen KW, Thompson DI: Social desirability is associated with some physical activity, psychosocial variables and sedentary behavior but not self-reported physical activity among adolescent males. Health Educ Res 2007, 22:3.

24. Motl RW, McAuley E, DiStefano C: Is social desirability associated with self-reported physical activity? Prev Med 2005, 40:735-739.

25. Morisky DE, Ang A, Sneed CD: Validating the effects of social desirability on self-reported condom use behavior among commercial sex workers. AIDS Educ Prev 2002, 14:351-360.

26. Ritter $\mathrm{P}$, Lorig K, Laurent $\mathrm{D}$, Matthews $\mathrm{K}$ : Internet versus mailed questionnaires: a randomized comparison. J Med Internet Res 2004, 6:e29.

27. Wu RC, Thorpe K, Ross H, Micevski V, Marquez C, Straus SE: Comparing administration of questionnaires via the Internet to pen-and-paper in patients with heart failure: randomized controlled trial. $J$ Med Internet Res 2009, 11:e3

28. Nagelhout GE, Willemsen MC, Thompson ME, Fong GT, Van den Putte B, De Vries $\mathrm{H}$ : Is web interviewing a good alternative to telephone interviewing? Findings from the International Tobacco Control (ITC) Netherlands Survey. BMC Public Health 2010, 10:351.

29. AAPOR: AAPOR Report on Online Panels Deerfield, IL: AAPOR; 2010

30. Klein JD, Thomas RK, Sutter EJ: Self-reported smoking in online surveys: prevelance estimate validity and item format effects. Med Care 2007, 45:691-695.

31. Best foot forward: social desirability in telephone vs. online surveys. [http://www.publicopinionpros.norc.org/from_field/2005/feb/taylor.asp].

32. Richman WL, Kiesler S, Weisband S, Drasgow F: A meta-analytic study of social desirability distortion in computer-administered questionnaires, tradition questionnaires, and interviews. J Appl Psychol 1999, 84:754-775.

33. Crowne DP, Marlowe D: A new scale of social desirability independent of psychopathology. Journal of Consulting Psychology 1960, 24:349-354.

34. Li A, Bagger J: The Balanced Inventory of Desirable Responding (BIDR): a reliability generalization study. Educ Psychol Meas 2007, 67:525-544.

35. Gawronski B, LeBel EP, Peters KR: What do implicit measures tell us? Scrutinizing the validity of three common assumptions. Perspect Psychol Sci 2007, 2:181-193.

36. Paulhus DL: Assessing self deception and impression management in selfreports: the Balanced Inventory of Desirable Responding Vancouver: University of British Columbia; 1988. 
37. Stöber J: The Social Desirability Scale-17 (SDS-17): Convergent validity, discriminant validity, and relationship with age. European Journal of Psychological Assessment 2001, 17:222-232.

38. Start of the LISS panel: sample and recruitment of a probability-based Internet panel. [http://www.lissdata.nl/assets/uploaded/Sample\%20and\% 20Recruitment_1.pdf].

39. Imputation of income in household questionnaire LISS panel. [http:// www.lissdata.nl//dataarchive/hosted_files/download/24].

40. Fischer DG, Fick C: Further validation of three short forms of the Marlowe-Crowne Scale of Social Desirability. Psychol Rep 1989, 65:595-600.

41. Trimbos Instituut: Nationale Drug Monitor [National Drug Monitor] Utrecht: Trimbos Instituut; 2007

42. Box GEP, Cox DR: An analysis of transformations. Journal of the Royal Statistical Society 1964, 26:211-252.

43. Fairchild AJ, MacKinnon DP: A general model for testing mediation and moderation effects. Prev Sci 2009, 10:87-99.

44. Chinn S: A simple method for converting an odds ratio to effect size for use in meta-analysis. Stat Med 2000, 19:3127-3131.

45. Daly LE: Confidence intervals and sample sizes: don't throw out all your old sample size tables. British Medical Journal 1991, 302:333-336.

46. Musch J, Brockhaus R, Bröder A: Ein Inventar zur Erfassung von zwei Faktoren sozialer Erwünschtheit [An inventory for the assessment of two factors of social desirability]. Diagnostica 2002, 48:121-129.

47. Göritz AS: Recruitment for online access panels. Int J Market Res 2004, 46:411-425.

48. Mudde AN, Willemsen MC, Kremers S, De Vries H: Meetinstrumenten voor onderzoek naar roken en stoppen met roken [Measurement instruments for research on smoking and smoking cessation]. 2 edition. Den Haag: STIVORO voor een rookvrije toekomst; 2006.

49. Tourangeau R, Smith TW: Asking sensitive questions: the impact of data collection mode, question format, and question context. Public Opin Quart 1996, 60:275-304.

50. Di Stefano J: A confidence interval approach to data analysis. Forest Ecol Manag 2004, 187:173-183.

51. Downey KK, Helmus TC, Schuster CR: Contingency management for accurate predictions of urinalysis test results and lack of correspondence with self-reported drug use among polydrug abusers. Psychol Addict Behav 2000, 14:69-72.

52. Dillon FR, Turner CW, Robbins MS, Szapocznik J: Concordance among biological, interview, and self-report measures of drug use among African American and Hispanic adolescents referred for drug abuse treatment. Psychol Addict Behav 2005, 19:404-413.

53. Ledgerwood DM, Goldberger BA, Risk NK, Lewis CE, Price RK: Comparison between self-report and hair analysis of illicit drug use in a community sample of middle-aged men. Addict Behav 2008, 33:1131-1139.

54. Bernaards CM, Twisk JWR, Van Mechelen W, Snel J, Kemper HCG: Comparison between self-report and a dipstick method (NicCheck 1) to assess nicotine intake. Eur Addict Res 2004, 10:163-167.

55. Mundle G, Ackermann K, Günther A, Munkes J, Mann K: Treatment outcome in alcoholism - a comparison of self-report and the biological markers carbohydrate-deficient transferrin and $\mathrm{\gamma}$-glutamyl transferase. Eur Addict Res 1999, 5:91-96.

56. Gmel G, Lokosha O: Self-reported frequency of drinking assessed with a closed- or open-ended question format: a split-sample study in Switzerland. J Stud Alcohol Drugs 2000, 61:450-454.

57. Göritz AS: The long-term effect of material incentives on participation in online panels. Field Methods 2008, 20:211-225.

\section{Pre-publication history}

The pre-publication history for this paper can be accessed here: http://www.biomedcentral.com/1471-2458/10/720/prepub

doi:10.1186/1471-2458-10-720

Cite this article as: Crutzen and Göritz: Social desirability and selfreported health risk behaviors in web-based research: three longitudinal studies. BMC Public Health 2010 10:720. 